\title{
General Psychiatry Pattern, clinical and demographic profile of inpatient psychiatry referrals in a tertiary care teaching hospital: a descriptive study
}

To cite: Mudgal V, Rastogi P, Niranjan V, et al. Pattern, clinical and demographic profile of inpatient psychiatry referrals in a tertiary care teaching hospital: a descriptive study. General Psychiatry 2020;33:e100177. doi:10.1136/ gpsych-2019-100177

Received 24 October 2019 Revised 07 May 2020 Accepted 09 May 2020
Check for updates

(C) Author(s) (or their employer(s)) 2020. Re-use permitted under CC BY-NC. No commercial re-use. See rights and permissions. Published by BMJ.

Psychiatry, Mahatma Gandhi Memorial Medical College, Indore, Madhya Pradesh, India

Correspondence to Dr Pali Rastogi; dr.palirastogi73@gmail.com

\section{ABSTRACT}

Background Consultation liaison psychiatry (CLP) as a subspecialty is defined as the area of clinical psychiatry that encompasses clinical understanding, teaching and research activities of psychiatrists and allied health professionals in the non-psychiatric divisions of a genera hospital. Psychiatric comorbidity of inpatients in tertiary care hospitals is huge. However, the amount of research in India in the field of consultation liaison is strikingly low.

Aim To investigate the sociodemographic profile and psychiatric and physical subtypes of illness in patients admitted in other departments and referred to psychiatry department.

Methods The study population comprised all consecutive inpatients referred for psychiatric consultation from other departments of a multispecialty tertiary care teaching hospital over 3 months. In a semistructured proforma, sociodemographic profile, referring departments, reasons for referral, referral rate, psychiatric diagnosis and physical illness diagnosis were recorded and analysed using descriptive statistics.

Results 172 patients were included and assessed after referral from various departments, of which $56.4 \%$ were male and $43.6 \%$ were female. The mean age was about 33.95 years, with majority of the patients in the $21-30$ years age group. The referral rate was $1.1 \%$. The maximum referrals were from the medicine department, with abnormal behaviour (26.2\%) being the most common reason for referral, followed by alleged suicide attempt or self-harm (24.4\%), anxiety (10.5\%), substance use (10\%) and disorientation (7.6\%). The most common psychiatric disorder among patients was depressive disorder (24.4\%), followed by substance use disorder (19.7\%), schizophrenia and psychotic disorder (9.3\%), and stress and trauma-related disorder (8.1\%).

Conclusion There are very few psychiatry referrals and an alarmingly low referral rate, given the psychiatric morbidities in the medical setting. Psychiatry training should have more weightage across different medical specialties and liaison activities between psychiatry and other disciplines should be augmented, which can lead to a better understanding of psychiatric symptomatology, early symptom recognition, swift referral and ensuring follow-up, which, in turn, would be key to improving CLP services.

\section{INTRODUCTION}

Consultation liaison psychiatry (CLP) is a field that combines psychiatry and other disciplines and includes clinical service, teaching and research on the cusp of psychiatry and medicine. 'Consultation-Liaison' demonstrates the inter-relatedness of psychiatry and clinical teaching and research, facilitating interdepartmental cooperation and effective patient management. ${ }^{1}$

The consultation part and liaison are reciprocally complementary. 'Consultation' pertains to the expert opinion provided about the diagnosis, followed by advice on management strategies of a patient's mental state and behaviour at the request of a health professional of another discipline. 'Liaison' refers to joining up of groups for effectual collaboration.

Participants in liaison psychiatry quite commonly find that the diagnosis and management of psychiatric disorders in the general hospital are a compound, tiresome and timeconsuming process. Liaison psychiatrists need to integrate a broad range of communication skills, as well as clinical, diagnostic, medical, legal and pharmacological skills. ${ }^{2}$

The most common reasons for referrals are psychological complications of a medical disorder; cognitive impairment associated with a medical disorder; functional symptoms; abnormal behaviour leading to psychiatric complications: deliberate self-harm, substance abuse and eating disorder; and physical and psychiatric disorders occurring at the same time. $^{2}$

Other frequent emotions, behaviours and symptoms patients exhibit that draw the attention of healthcare professionals and result in a psychiatric consultation request are depression and suicidal behaviour, altered states of consciousness/delirium, anxiety and agitated behaviour, psychotic symptoms, suspected 
psychogenic physical symptoms, addiction and pain problems.

Co-occurrence of mental and general medical disorders is one of the most common and disabling combinations, with approximately $30 \%$ of individuals with comorbidity having both a mental and a physical disorder. ${ }^{3}$

Striking contrast exists between India and other developed nations in the context of research in CLP. CLP is a specialty branch which falls between psychiatry and medicinal discipline, however abjectly not fully accepted by either. In settings of tertiary care centres and specialty hospitals, there is a dearth of literature regarding inpatient psychiatry referrals, especially in the Indian scenario. The purpose of the current research was to throw light on various clinical and demographic profiles of inpatient psychiatry referrals obtained in a tertiary care multispecialty hospital.

\section{MATERIALS AND METHODS}

The study was descriptive in nature and included all consecutive referrals from inpatients of other departments to the psychiatry department within the 3-month study duration lasting from January 2018 to March 2018 at Mahatma Gandhi Memorial Medical College, Indore, Madhya Pradesh, India. Eligibility criteria included inpatient admitted to any department of the hospital other than psychiatry department and of either sex. No age limits were set. Patients were recruited from MY (Maharaja Yashwantrao) Hospital, which has a capacity of 1200 beds. About 18720 patients were admitted to MY Hospital between January 2018 and March 2018, of which 207 inpatients belonged to the psychiatry department and were therefore excluded. All consecutive inpatient referrals from other departments were included in the study irrespective of their diagnosis; 205 referrals were received, of which 15 patients absconded or left against medical advice before assessment could be done. During the course of the study, 18 patients refused to participate. Hence, out of a total of 205 referrals, 172 patients were included in the study (figure 1). Outpatient-based referrals and patients admitted to the psychiatry department were excluded. A semistructured proforma was created for the participants with regard to demographic information, departmentwise referral, reason for referral, presenting complaints, physical diagnosis, history of psychiatric illness, family history, substance use history and psychiatric diagnosis. After detailed description of the study, written informed consent was taken from the patients. The International Statistical Classification of Diseases and Related Health Problems-10 was used to decide the psychiatric diagnosis of the referred inpatients. Data obtained were analysed using descriptive statistical methods.

\section{RESULTS}

\section{Sociodemographic distribution}

A total of 205 patients were referred for psychiatric consultation from various departments during the study
Table 1 Demographic details

\begin{tabular}{|c|c|c|}
\hline Variable & Frequency $(\mathrm{N}=172)$ & Percentage \\
\hline Mean age (SD) & $33.95(15.10)$ & - \\
\hline \multicolumn{3}{|l|}{ Marital status } \\
\hline Married & 118 & 68.6 \\
\hline Unmarried & 48 & 27.9 \\
\hline N/A & 6 & 3.5 \\
\hline \multicolumn{3}{|l|}{ Education } \\
\hline Uneducated & 44 & 25.5 \\
\hline Primary & 55 & 31.9 \\
\hline High school & 40 & 23.2 \\
\hline Intermediate & 22 & 12.7 \\
\hline Graduate & 11 & 6.4 \\
\hline \multicolumn{3}{|l|}{ Occupation } \\
\hline Unemployed & 113 & 66 \\
\hline Unskilled worker & 13 & 7.5 \\
\hline Semiskilled worker & 26 & 16 \\
\hline Skilled worker & 3 & 1.5 \\
\hline Shop owner/farmer & 11 & 6.5 \\
\hline Professional & 6 & 3.5 \\
\hline \multicolumn{3}{|l|}{ Locality } \\
\hline Urban & 126 & 73.3 \\
\hline Rural & 46 & 26.7 \\
\hline \multicolumn{3}{|l|}{ Family } \\
\hline Joint & 136 & 79.1 \\
\hline Nuclear & 36 & 20.9 \\
\hline \multicolumn{3}{|l|}{ Religion } \\
\hline Hindu & 137 & 79.7 \\
\hline Muslim & 26 & 15.1 \\
\hline Sikh & 2 & 1.2 \\
\hline Christian & 1 & 0.6 \\
\hline N/A & 6 & 3.5 \\
\hline
\end{tabular}

$\mathrm{N} / \mathrm{A}$, not available.

period, 172 of which were included in the study. Out of the 172 patients, $97(56.4 \%)$ were male and $75(43.6 \%)$ were female. The mean age of the patients was 33.95 (15.10) years, ranging from 14 to 80 years. The majority of the patients belonged to the 20-40years age group $(n=114,66.27 \%)$. The number of patients in the age group below 20 years and above 60 years was 35 (20.3\%) and $13(7.5 \%)$, respectively. The rest of the demographic variables are shown in table 1 . Few patients were unknown and so demographic details could not be obtained.

\section{Referring department}

Table 2 shows the department-wise number of psychiatric referrals. Majority of the referrals were from the medicine department $(n=131,76.2 \%)$. Other contributors to psychiatric referrals were the departments of surgery 
Table 2 Referring department

\begin{tabular}{lcc}
\hline Department & Frequency & Percentage \\
\hline Medicine & 131 & 76.2 \\
Surgery & 23 & 13.4 \\
Obstetrics and & 11 & 6.4 \\
gynaecology & & \\
Orthopaedic & 6 & 3.5 \\
Ophthalmology & 1 & 0.6 \\
Total & 172 & 100.0 \\
Referral rate & $1.1 \%$ & \\
\hline
\end{tabular}

$(\mathrm{n}=23,13.4 \%)$ and obstetrics and gynaecology $(\mathrm{n}=11$, $6.4 \%)$.

\section{Reasons for referral}

Table 3 presents the various reasons for which referrals were called for. The most common reason for referral was having an abnormal behaviour $(\mathrm{n}=45,26.2 \%)$, followed by alleged suicide attempt or self-harm $(\mathrm{n}=42,24.4 \%)$, anxiety $(\mathrm{n}=18,10.5 \%)$, substance use $(\mathrm{n}=17,10 \%)$ and disorientation $(\mathrm{n}=13,7.6 \%)$.

\section{Psychiatric diagnosis}

Table 4 shows the distribution of various psychiatric diagnoses in the sample. The most common psychiatric disorder among the consulted patients was major depressive disorder (MDD) (24.4\%), followed by substance use disorder (19.7\%), schizophrenia and psychotic disorder $(9.3 \%)$, and stress and trauma-related disorder $(6.9 \%)$. About 19.2\% of patients had no psychiatric disorder. The sum of the proportions shown is more than $100 \%$ since many individual patients had multiple psychiatric disorders.

\section{Physical diagnosis}

Table 5 shows the distribution of various physical (medical/surgical) diagnoses in the referred sample. As there were numerous diagnoses, they were grouped as per the organ system involved/aetiology. The most common group belonged to poisoning, injury and burn

\section{Table 3 Reasons for referral}

\begin{tabular}{lcc}
\hline Reason & Frequency & Percentage \\
\hline Suicide/self-harm & 42 & 24.4 \\
$\begin{array}{l}\text { Abnormal behaviour/ } \\
\text { agitation }\end{array}$ & 45 & 26.2 \\
Disorientation & 13 & 7.6 \\
Depression & 12 & 7.0 \\
Substance use & 17 & 9.9 \\
Psychiatric history & 2 & 1.2 \\
Anxiety & 18 & 10.5 \\
Others & 23 & 13.4 \\
Total & 172 & 100.0 \\
\hline
\end{tabular}

Table 4 Psychiatric diagnosis

\begin{tabular}{lcc}
\hline Disorder & Frequency & Percentage \\
\hline Delirium & 7 & 4 \\
Dementia & 6 & 3.5 \\
\hline $\begin{array}{l}\text { Organic psychosis/mood } \\
\text { disorder }\end{array}$ & 10 & 5.8 \\
Substance use disorder & 34 & 19.7 \\
\hline Schizophrenia/psychosis & 16 & 9.3 \\
\hline Depression & 42 & 24.4 \\
\hline Bipolar disorder & 5 & 2.9 \\
\hline Trauma/stress disorders & 12 & 6.9 \\
\hline Somatoform disorders & 2 & 1.1 \\
\hline Anxiety disorders & 2 & 1.1 \\
\hline Personality disorders & 2 & 1.1 \\
\hline Dissociative disorders & 11 & 6.4 \\
\hline Deliberate self-harm & 8 & 4.6 \\
\hline Epilepsy & 8 & 4.6 \\
\hline Puerperium-related & 3 & 1.7 \\
\hline Others & 4 & 2.3 \\
\hline No psychiatric disorder & 33 & 19.2 \\
\hline
\end{tabular}

$(\mathrm{n}=63,36.6 \%)$, followed by central nervous system disorders $(\mathrm{n}=18,10.5 \%)$, cardiovascular system disorders $(\mathrm{n}=15,8.7 \%)$, gastrointestinal system disorders $(\mathrm{n}=12$, $7 \%)$ and respiratory system disorders $(\mathrm{n}=11,6.4 \%)$. The sum of the proportions shown is more than $100 \%$ since many individual patients had multiple system disorders.

\section{DISCUSSION}

\section{Main findings}

The current study was undertaken to evaluate the demographic and clinical variables of inpatient psychiatry

\begin{tabular}{|c|c|c|}
\hline System & Frequency (n) & Percentage \\
\hline Infectious & 8 & 4.6 \\
\hline Endocrine & 5 & 2.9 \\
\hline Metabolic & 7 & 4 \\
\hline Central nervous system & 18 & 10.5 \\
\hline Cardiovascular system & 15 & 8.7 \\
\hline Respiratory & 11 & 6.4 \\
\hline Gastrointestinal & 12 & 7 \\
\hline Connective & 4 & 2.3 \\
\hline Genitourinary & 2 & 1.2 \\
\hline Haematological & 3 & 1.7 \\
\hline Obstetrics/gynaecology & 11 & 6.4 \\
\hline Poison/injury/burn & 63 & 36.6 \\
\hline Others & 22 & 12.8 \\
\hline
\end{tabular}




\section{We received 205 consecutive inpatient psychiatric referrals from other departments at M. Y Hospital Indore between January and March in 2018.}

33 patients excluded :

--- 15 patients absconded or left against medical advice before the assessment. --- 18 patients refused to participate in the study or unwilling to give consent.

172 included in the study, interviewed as per our protocol, and analysed

Figure 1 Flow chart of sample selection. The study was conducted between January 2018 and March 2018 . All consecutive psychiatric inpatient referrals from other departments were included in the study irrespective of their diagnosis. 205 referrals were received. 33 patients were excluded, of which 15 absconded or left against medical advice before assessment could be done, while 18 refused to participate in the study. Hence out of a total of 205 referrals, 172 patients were included in the study.

referrals from other departments in a tertiary care teaching hospital. The majority of referrals were in the $20-40$ years age range $(66.2 \%)$, with a mean age of $33.95(15.10)$ years. This observation is consistent with the findings of Tekkalaki $e t a l,{ }^{4}$ who reported a mean age of 35.53 years. Similarly about $63.9 \%$ of patients in the $16-45$ years age range was observed by Avasthi $e t a l,{ }^{5}$ along with Bhogale $e t$ $a l,{ }^{6}$ who reported concurring results.

Gender distribution showed male dominance (56.4\%), which is similar to the results of Chaudhury et $a l^{7}$ and Keertish $e t a l,{ }^{8}$ who reported a male distribution of $70 \%$ and $58 \%$, respectively.

Our study displayed literacy rate of about $75 \%$, with $25.5 \%$ of the sample uneducated and the majority with up to high school education. This corresponds to the results of Desai $e t a t^{\dagger}$ and to the regional distribution of literacy and education in India.

Majority of the patients were married $(68.6 \%)$. The greater number of married patients in the current study could be secondary to the majority of sample population belonging to the 21-60 years age group. A huge chunk of the patients were Hindu by religion $(79.7 \%)$, which conforms with Desai $e t$ a $t^{\ominus}$ and replicates the customary religious demographics in the sampling area under consideration. Most patients belonged to nuclear family $(79.1 \%)$ and had an urban background $(73.3 \%)$.

Out of 18513 inpatients (18720 inpatients, 207 psychiatry inpatients excluded), a meagre 205 psychiatric referrals were received, bringing the referral rate to about $1.1 \%$. Various other studies have shown a similar low referral rate: $0.42 \%$ in Keertish $e t a l^{8}$ and $1.01 \%$ in Rastogi et $a l^{10}$ in India; $0.63 \%$ in Ji and Ye, ${ }^{11} 1.32 \%$ in CY et al, ${ }^{12}$ and $1.01 \%$ in Cui et al $^{13}$ in China; $3.78 \%$ in Risal and Sharma ${ }^{14}$ in Nepal; $1.8 \%$ in Gangat ${ }^{15}$ in South Africa; and $1.19 \%$ in Arbabi $e t a l^{16}$ in Iran. This implicates a very pitiful state of consultation liaison considering the alarming comorbidity rate in psychiatry $(18.42 \%-53.7 \%)$, as determined by other researchers who have surveyed other disciplines for psychiatric disorders. ${ }^{17}$
In our assessment of referring departments, it was observed that the internal medicine department was the leading discipline when it comes to sending referrals. This was in accordance with other previous Indian studies. ${ }^{458}$ Comparing our results with other countries, YW et $a l,{ }^{18}$ Jiang, ${ }^{19}$ Lin et $a l^{20}$ and Yang ${ }^{21}$ in China, Risal and Sharma ${ }^{14}$ in Nepal, and Tema ${ }^{22}$ in South Africa also showed that most referrals were received from internal medicine. The reason for this could be that psychiatry is a medicine specialty where physicians frequently encounter illnesses with psychological component and thus they are more psychiatrically oriented. Moreover, in addition to low awareness among people, social stigma in the context of psychiatric illness and seeing a psychiatrist is very high, and thus physicians are preferred over psychiatrists.

When reasons for referrals were analysed, abnormal behaviour and agitation (26.2\%) topped the list, followed by suicide/self-harm $(24.2 \%)$. This finding is consistent with the study done by Rastogi et $a l^{10}{ }^{10}$ where it was ascertained that altered level of consciousness and aberrant behaviour, along with psychosis-related behaviour, were the leading reasons for referral, representing $31.9 \%$. Tekkalaki et al ${ }^{4}$ found self-harm to be the second leading cause, while Niranjan and Udey ${ }^{23}$ found abnormal behaviour to be the most common cause at $30.9 \%$, similar to our study. A significant amount of psychiatric cases among admitted patients are neither recognised nor referred to psychiatrists by general physicians in general hospitals, and such cases are not evaluated for psychopathology with the same enthusiasm as for medical symptoms. Therefore usually when agitation or an abnormal behaviour of patients gets beyond the threshold of the managing staff, only then psychiatric consultation becomes prudent; however, psychological and affective disturbances which are not very troublesome do not warrant psychiatric referral. ${ }^{15} 23$ The medicolegal implications of suicidal behaviour and self-harm result in a psychiatric referral in almost all cases admitted for the same, which is clearly reflected in the hierarchical 
placement of suicidality and self-harm as the second leading reasons for referral.

In the present study, MDD/depression (24.4\%) was found to be the most common psychiatric disorder, followed by substance use disorder and schizophrenia and psychotic disorders. Affective disorder made up $27.3 \%$ of all diagnoses, and these findings corroborate with Risal and Sharma, ${ }^{14}$ Arbabi et al, ${ }^{16}$ Tema et al,${ }^{22}$ Shah, ${ }^{24}$ Singh $e t a l,{ }^{25} \mathrm{Su} e t a l^{26}$ and Ozkan. ${ }^{27}$ The category of substance use subsumed intoxication, withdrawal states, dependence syndromes, and mental and behavioural disorders induced by substance. Keertish $e t a l,{ }^{8}$ Risal and Sharma ${ }^{14}$ and Bourgeois $e t a l^{28}$ found results that are in concordance to our findings.

Many studies such as from India ${ }^{4510}$ and a review of CLP in China by Ji and $\mathrm{Ye}^{11}$ suggest organic mental disorders to be the leading factor in psychiatric diagnosis. However, the relative lack of organic mental disorders $(5.8 \%)$, similar to the findings of Keertish $e t a l^{8}$ and Risal and Sharma, ${ }^{14}$ could be attributed to the presence of trained neurology specialists in our tertiary centre who are comfortable in dealing with such conditions, in turn leading to fewer referrals of such cases.

About $19 \%$ of the patients we assessed did not have any psychiatric diagnoses, which is similar to Tekkalaki et at $t^{t}$ and Rastogi et $a l^{10}$ which showed $31 \%$ and $28.5 \%$ referrals with inconclusive or no psychiatric diagnosis, respectively. This can be attributed to patients with accidental poisoning, accidents, agitation and insomnia secondary to pain, language barrier misconstrued as irrelevant talk, and so on being considered to have no psychiatric disorder. It also implies a relative lack of understanding of psychiatric symptomatology by other disciplines and a need to sensitise medical fraternity regarding psychiatric comorbidity, as many referrals were done without proper investigations and lack of proper communication with patients, which negatively affect patient management.

On assessment of the physical axis of diagnosis, including medical and surgical conditions, it was observed that the most common condition was attributed to trauma and injury secondary to poisoning, burn and blunt trauma/ fracture $(30 \%)$. The findings of the current study are in accordance with the study by Niranjan and Udey ${ }^{23}$ and Christodoulou et al, ${ }^{29}$ who reported that the most common physical illness was of injuries and poisoning, with central nervous system disorders and cardiovascular system involvement the other leading physical disorders.

\section{Limitations}

Despite all the efforts and inputs, there are few limitations to our study which should be considered while interpreting the results, such as the use of purposive sampling, the study's limited duration, lack of follow-up, not longitudinal in nature and reliance on patient report without supporting methods like inter departmental liaison, joint rounds, case conferences. Hence the results cannot be generalised to all settings.

\section{Implications}

Consultation liaison is a developing branch in India and needs more attention. In accordance with earlier studies, it has been demonstrated that there are very few psychiatry referrals and an alarmingly low referral rate, in proportion to the psychiatric morbidities in medical setting. We suggest that psychiatry training should be given more weightage in the undergraduate medical curriculum, and that more liaison activities such as regular interdepartmental meets, case conferences and seminars should be organised between psychiatry and other disciplines, so that a better understanding of psychiatric symptomatology, early symptom recognition, swift referral and follow-up can be ensured, which would be key to improving CLP services. There is an urgent need to improve CLP services and training to provide the best and optimal care to patients and to cater the best education to the medical staff.

We found that a significant proportion of the young productive age group were referred. Patients suffering from almost all types of medical or surgical illnesses were also referred for some or other behavioural complaints. Most of the existing literature published in relation to CLP services has been inexplicit with regard to functional aspect and ways of improving services.

Further research is warranted, especially longitudinal studies on outcome variables with respect to various clinical processes, such as interviews, length of visits and follow-up activities. In addition, future studies need to assess the knowledge and attitudes of patients, families and healthcare providers regarding mental illness, C-L(Consultation- Liaison) service, barriers and so on. The findings from such assessments will help with cultural and organisational changes to better integrate C-L service into a general hospital.

\section{Twitter Varchasvi Mudgal @varchasvi04}

Acknowledgements We would like to thank all the participants and the authors of the literature used in the study for their kind cooperation and contribution, along with colleagues at MY Hospital.

Contributors Study conception and design: VM, PR. Acquisition of data: VM. Analysis and interpretation of data: VM, VN. Drafting of the manuscript: VM, PR, VN. Critical revision: $\mathrm{RR}$.

Funding The authors have not declared a specific grant for this research from any funding agency in the public, commercial or not-for-profit sectors.

Disclaimer We certify that no party having a direct interest in the results of the research supporting this article has or will confer a benefit on us or on any organisation with which we are associated, and we certify that all financial and material support for this research and work are clearly identified in the manuscript.

\section{Competing interests None declared.}

Patient consent for publication Not required.

Ethics approval Ethical clearance from the institutional ethical committee of the hospital was obtained before the study commenced.

Provenance and peer review Not commissioned; externally peer reviewed.

Data availability statement All data relevant to the study will be provided upon reasonable request. The data contain all participant details collected during the research after deidentification. Data can be used immediately after publication by anyone who wishes to use the data to achieve the aims as per the current study. 
Proposal for data request can be sent up to 5 years after publication by email ( varchasvimudgal04@gmail.com).

Open access This is an open access article distributed in accordance with the Creative Commons Attribution Non Commercial (CC BY-NC 4.0) license, which permits others to distribute, remix, adapt, build upon this work non-commercially, and license their derivative works on different terms, provided the original work is properly cited, appropriate credit is given, any changes made indicated, and the use is non-commercial. See: http://creativecommons.org/licenses/by-nc/4.0/.

ORCID iD

Varchasvi Mudgal http://orcid.org/0000-0002-7078-6710

\section{REFERENCES}

1 Lipowski ZJ. Current trends in consultation-liaison psychiatry. Can J Psychiatry 1983;28:329-38.

2 Leigh H, Guthrie E. Handbook of consultation-liaison psychiatry. 1st Edn. Cambridge: Cambridge Press, 2007.

3 Walker ER, Druss BG. A public health perspective on mental and medical comorbidity. JAMA 2016;316:1104.

4 Tekkalaki B, Tripathi A, Arya A, et al. A descriptive study of pattern of psychiatric referrals and effect of psychiatric intervention in consultation-liaison set up in a tertiary care center. Indian J Soc Psychiatry 2017;33:165.

5 Avasthi A, Sharan P, Kulhara P, et al. Psychiatric profiles in medicalsurgical populations : need for a focused approach to consultationuaison psychiatry in developing countries. Indian J Psychiatry 1998;40:224-30.

6 Bhogale GS, Katte RM, Heble SP, et al. Psychiatric referrals in multispeciality Hospital. Indian J Psychiatry 2000;42:188-94.

7 Chaudhury S, Singh G, Saldanha D, et al. Psychiatric emergency referrals in a tertiary care hospital. Med J DY Patil Vidyapeeth 2018;11:312.

8 Keertish N, Sathyanarayana MT, Kumar BGH, et al. Pattern of psychiatric referrals in a tertiary care teaching hospital in southern India. J Clin Diagn Res 2013;7:1689-91.

9 Desai N, Shah S, Shah S, et al. Psychiatric referrals in tertiary care hospital. Natl J Integr Res Med 2016;7:56-60.

10 Rastogi R, Madhusudan KK, Verma P, et al. Psychiatric referral characteristics at a tertiary care Hospital: a fresh appraisal. Indian $J$ of Social Psychiatry 2011;27:165-9.

$11 \mathrm{Ji}$ J, Ye C. Consultation-Liaison psychiatry in China. Shanghai Arch Psychiatry 2012;24:124-30.

12 CY Y, Shen YF, Ling Z, et al. Psychiatric consultation for medical patients and follow-up study in general Hospital. Shanghai Arch Psychiatry 2006;18:20-3.

13 Cui LQ, Huang YP, JL Y. Analysis of consultation liaison for respiratory patients at a general Hospital. MMJC 2011;13:28-31.
14 Risal A, Sharma PP. Psychiatric morbidity patterns in referred inpatients of other specialties. JNMA J Nepal Med Assoc 2013;52:238-44.

15 Gangat AE, Naidoo LR, Simpson MA. Referral patterns for psychiatric consultation in a large General Hospital. S Afr Med J 1987;72:853-5

16 Arbabi M, Laghayeepoor R, Golestan B, et al. Diagnoses, requests and timing of 503 psychiatric consultations in two general hospitals. Acta Med Iran 2012;50:53-60.

17 Grover S. State of consultation-liaison psychiatry in India: current status and vision for future. Indian J Psychiatry 2011;53:202.

18 YW L, Shen QJ, JZ H, et al. A two years consultation reviewed of mental department in Shenzhen hospitals. Medical $J$ of Chinese People's Health 2002;14:135-7.

19 Jiang H, Jia JH, Tang ZX. Analysis of consultation-liaison psychiatry for inpatients in general hospitals. Chin J Rehabil Theory Practice 2003;9:695.

20 Lin ZX, Zou XB, Lin JD, et al. Departments applying for consultationliaison psychiatry and distribution of diagnosed different psychiatric diseases in general hospitals: Analysis of 154 cases. Chinese Journal of Clinical Rehabilitation 2006;10:172-3.

21 Yang SY, JL L. Results of consultation-liaison referral for General Hospital inpatients with a comorbid psychiatric illness. J Clin Psychosom Dis 2009;6:544-5.

22 Tema NSZ, Janse van Rensburg ABR, Rensburg B. Psychiatric consultations and the management of associated comorbid medical conditions in a regional referral hospital. South African Journal of Psychiatry 2015;21:6.

23 Niranjan V, Udey B. Clinical and demographical profile of inpatient psychiatry referrals in a Multispecialty teaching hospital. Open $J$ Psychiatry Allied Sci 2017;8:153.

24 Shah P. Trend of psychiatric disorders among out-patients and in-patients of a tertiary care center of India. Int J Res Med Sci 2014;2:439.

25 Singh PM, Vaidya L, Shrestha DM, et al. Consultation liaison psychiatry at Nepal medical college and teaching hospital. Nepal Med Coll J 2009;11:272-4.

26 Su J-A, Chou S-Y, Chang C-J, et al. Changes in consultation-liaison psychiatry in the first five years of opearation of a newly-opened Hospital. Chang Gung Med J 2010;33:292-300.

27 Ozkan M. An evaluation of the Department of consultation liaison psychiatry in Istanbul faculty of medicine: psychiatry consultation in 14 years. J Ist Faculty Med 2005;68:105-12.

28 Bourgeois JA, Wegelin JA, Servis ME, et al. Psychiatric diagnoses of 901 inpatients seen by consultation-liaison psychiatrists at an academic medical center in a managed care environment. Psychosomatics 2005;46:47-57.

29 Christodoulou C, Fineti K, Douzenis A, et al. Transfers to psychiatry through the consultation-liaison psychiatry service: 11 years of experience. Ann Gen Psychiatry 2008;7:10.

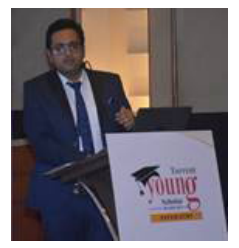

Dr. Varchasvi Mudgal is a third year post-graduate resident at M.G.M Medical College Indore, M.P which is affiliated to MPMS University Jabalpur, M.P, India. He completed his bachelor's degree of medicine (M.B.B.S) from Pt. J.N.M Medical College affiliated to Ayush Health University in Raipur, C.G, India. His thesis dissertation was about inflammatory markers in suicide and had promising results. He is currently working as an academic resident in a multi-speciality hospital associated with a tertiary mental hospital and de-addiction centre. He has won the coveted national level Torrent Young Scholar Award for Psychiatry in 2019. His main research interests include depression, suicide, substance use disorder, and consultation liaison psychiatry. 